Article

\title{
Efficient Purification of R-phycoerythrin from Marine Algae (Porphyra yezoensis) Based on a Deep Eutectic Solvents Aqueous Two-Phase System
}

\author{
Yifeng $\mathrm{Xu}{ }^{1}$, Quanfu Wang ${ }^{1,2, *}$ and Yanhua Hou ${ }^{2, *}$ \\ 1 School of Environment, Harbin Institute of Technology, Harbin 150090, China; 16B927074@stu.hit.edu.cn \\ 2 School of Marine Science and Technology, Harbin Institute of Technology, Weihai 264209, China \\ * Correspondence: wangquanfuhit@hit.edu.cn (Q.W.); houyanhuahit@hit.edu.cn (Y.H.); \\ Tel.: +86-631-568-7240 (Q.W. \& Y.H.)
}

Received: 24 September 2020; Accepted: 2 December 2020; Published: 4 December 2020

check for updates

\begin{abstract}
R-phycoerythrin (R-PE), a marine bioactive protein, is abundant in Porphyra yezoensis with high protein content. In this study, R-PE was purified using a deep eutectic solvents aqueous two-phase system (DES-ATPS), combined with ammonium sulphate precipitation, and characterized by certain techniques. Firstly, choline chloride-urea (ChCl-U) was selected as the suitable DES to form ATPS for R-PE extraction. Then, single-factor experiments were conducted: the purity $\left(A_{565} / A_{280}\right)$ of R-PE was 3.825, and the yield was 69.99\% (w/w) under optimal conditions (adding $0.040 \mathrm{mg}$ R-PE to $\mathrm{ChCl}-\mathrm{U}(0.35 \mathrm{~g}) / \mathrm{K}_{2} \mathrm{HPO}_{4}(0.8 \mathrm{~g} / \mathrm{mL}, 0.5 \mathrm{~mL})$ and extracting for $\left.20 \mathrm{~min}\right)$. The sodium dodecyl sulfate-polyacrylamide gel electrophoresis (SDS-PAGE) results revealed that the purified R-PE contained three main bands. One band was presented after purification in native-PAGE. The UV-vis spectra showed characteristic absorption peaks at 495, 540, and $565 \mathrm{~nm}$. R-PE displayed an emission wavelength at $570 \mathrm{~nm}$ when excited at $495 \mathrm{~nm}$. All spectra results illustrated that the structure of R-PE remained unchanged throughout the process, proving the effectiveness of this method. Transmission electron microscope (TEM) showed that aggregation and surrounding phenomena were the driving forces for R-PE extraction. This study could provide a green and simple purification method of R-PE in drug development.
\end{abstract}

Keywords: aqueous two-phase system; deep eutectic solvent; extraction; marine algae; R-phycoerythrin

\section{Introduction}

R-phycoerythrin (R-PE) is a marine bioactive protein, mainly found in Rhodophyta, such as Grateloupia turuturu [1], Heterosiphonia japonica [2], and Porphyra yezoensis. Among them, Porphyra yezoensis is one of the major seaweeds abundantly cultivated in China [3]. It is easy to obtain, and the price is low. Besides, P. yezoensis has a higher protein content than other red algae $(47 \%$ of dry weight) $[4,5]$. Because of this, it has attracted increasing attention as a healthy food and as a medicine to slow down the ageing process $[3,6]$. R-phycoerythrin (R-PE) is one of the major phycobiliproteins in P. yezoensis. Its purity is generally calculated by the absorbance ratio $\left(\mathrm{A}_{565} / \mathrm{A}_{280}\right)$, and the market price is around $200 \mathrm{USD} / \mathrm{mg}$ (Sigma-Aldrich, product number: 52412-1MG-F) [7,8]. Therefore, R-PE is regarded as a bioactive molecule with high value. It has been reported that R-PE has numerous biological activities, including antioxidant [9], anti-inflammatory [10], anti-aging [11], and immunomodulatory activity [12,13]. R-PE has excellent optical properties as a natural fluorescent protein [1,14]. Based on these properties, R-PE has been widely applied in the biotechnological and medical fields. For example, it is used to treat cancer in photodynamic therapy as a model photosensitizer [15]. It is also used 
in immunology and cell biology and flow cytometry as a fluorescent label [16-18]. In addition, it is utilized in the food and cosmetics fields as a natural pigment [19]. In our previous study, R-PE was applied as a natural fluorescent probe to monitor mercury ions in water environments [20].

In view of the broad application prospects of R-PE, many conventional methods have been used for the extraction and purification of R-PE, such as ammonium sulfate precipitation combining with diethylaminoethyl (DEAE)-Sepharose Fast Flow column chromatography [1], hydroxyapatite column chromatography [14], and Q-Sepharose column chromatography [21]. These methods have their advantages and contribute in their own ways to R-PE purification yield. However, these purification procedures are usually needed high cost. In recent years, the aqueous two-phase system (ATPS), as a liquid-liquid extraction system, has offered an active alternative for extracting phycobiliprotein with high purity or improved extraction efficiency [22,23]. Usually, ATPS is composed of two polymers or a polymer and a salt in specific concentrations [24]. It can promise extraction of the desired substance in a relatively mild environment to ensure molecular stability throughout the extraction process.

With the development of green chemistry, green solvents have attracted notable attention. Deep eutectic solvents (DESs), as green solvents, are composed of a proper molar ratio of a hydrogen-bond acceptor (quaternary ammonium salts) and hydrogen-bond donors (acid amides, carboxylic acids, and polyhydric alcohols) $[25,26]$. As analogues of ionic liquids (ILs), DESs share many physicochemical properties with ILs, such as non-flammability, and excellent thermal and chemical stability [25]. DESs also have unique advantages, such as ease of preparation, and lower price and toxicity [27,28]. Therefore, DESs have been applied in the fields of electrochemistry [29], catalysts [30], and extraction of bioactive compounds, such as polyphenols [31], catechins [32], and proteins [33].

Based on the high commercial value and great application potential in food and medical field of $\mathrm{R}-\mathrm{PE}$, a low-cost purification method needed to be developed. To the best of our knowledge, there was no report on purifying R-PE using green solvent DES combined with ATPS. Therefore, the main focus of this study was to develop an environmentally friendly and low-cost method combining a green DES with ATPS, coupled with ammonium sulfate precipitation and applied to extract R-PE from the natural marine algae $P$. yezoensis, which had high protein content. Additionally, its properties and purification mechanisms were identified. The drug-grade R-PE (purity was 3.0) was obtained, and the method was cheaper.

\section{Results and Discussion}

\subsection{Characterization of DESs}

The structures of the obtained DESs are shown in Figure S1. The absorption bands of all DESs exhibited a remarkably broad and strong peak between $3300-3400 \mathrm{~cm}^{-1}$, contributing to the $\mathrm{OH}$ stretching bands at approximately $3300 \mathrm{~cm}^{-1}$, which represented the presence of abundant hydrogen bonds in the six kinds of DESs.

\subsection{Establishment and Phase Behavior of DES-Based ATPS}

The data of the DES-based phase diagram determined at $298.15 \mathrm{~K}$ and atmospheric pressure are shown in Figure $1 . \mathrm{K}_{2} \mathrm{HPO}_{4}$ was selected as the phase separation salt because of its strong phase-forming ability and high solubility in water [34]. According to the former literature report, if the phase diagram of DES- $\mathrm{K}_{2} \mathrm{HPO}_{4}$ is close to the origin of the coordinate axis, the phase-forming ability of the DES is stronger [25]. Therefore, the phase-forming abilities of the DESs were in following descending sequence: choline chloride-urea $(\mathrm{ChCl}-\mathrm{U})>$ choline chloride-D-glucose $(\mathrm{D}-\mathrm{ChCl}-\mathrm{Gl})>$ choline chloride-glycerol $(\mathrm{ChCl}-\mathrm{G})>$ choline chloride-D-fructose $(\mathrm{D}-\mathrm{ChCl}-\mathrm{F})>$ choline chloride-D-sorbitol $(\mathrm{D}-\mathrm{ChCl}-\mathrm{S})>$ choline chloride-ethylene glycol (ChCl-EG). It was presumed that the difference in abilities of these DESs to form phase was related to their affinity for water molecules $[35,36]$. The illustration corresponded to the sequence of the phase diagram from left to right: ChCl-U, D-ChCl-Gl, ChCl-G, D-ChCl-F, D-ChCl-S, and ChCl-EG. 


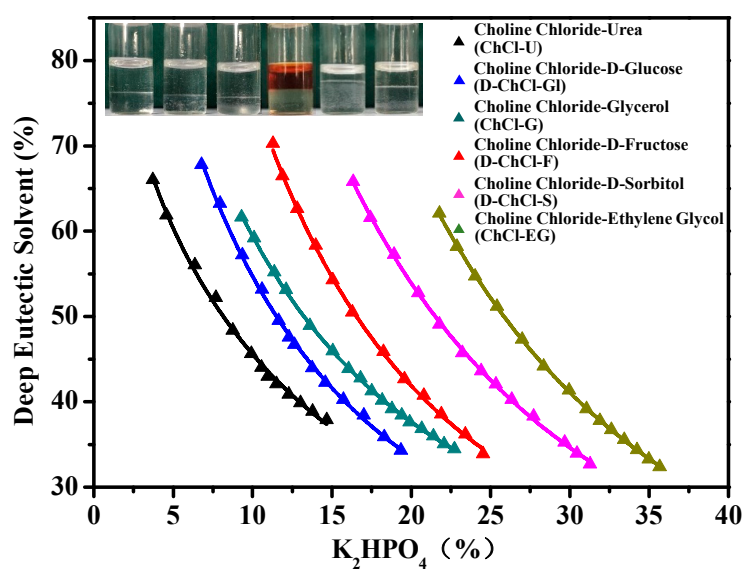

Figure 1. The phase diagrams of deep eutectic solvents (DESs) $+\mathrm{K}_{2} \mathrm{HPO}_{4}$ aqueous two-phase systems (ATPSs). ChCl-U represents choline chloride-urea, D-ChCl-Gl represents choline chloride-D-glucose, $\mathrm{ChCl}-\mathrm{G}$ represents choline chloride-glycerol, D-ChCl-F represents choline chloride-D-fructose, D-ChCl-S represents choline chloride-D-sorbitol, ChCl-EG represents choline chloride-ethylene glycol. The illustration showed six ATPSs in phase diagram order.

\subsection{Selection of DES-ATPS for the R-PE Extraction}

The DES-ATPSs above were investigated for R-PE extraction (as shown in Figure 2). Taking purity and extraction efficiency as the indicators, $\mathrm{ChCl}-\mathrm{U} / \mathrm{K}_{2} \mathrm{HPO}_{4}$ was the best system for R-PE purification among the six ATPSs. Therefore, $\mathrm{ChCl}-\mathrm{U} / \mathrm{K}_{2} \mathrm{HPO}_{4}$ was chosen as the extraction system for the subsequent study.

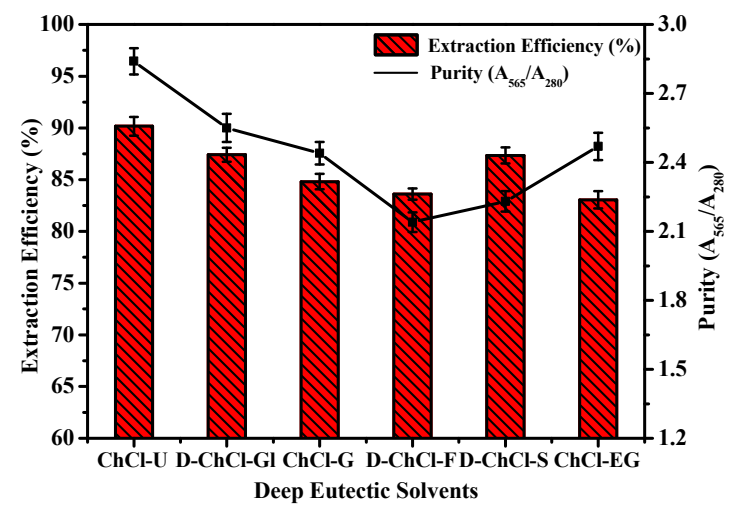

Figure 2. Effect of different deep eutectic solvents aqueous two-phase systems (DES-ATPSs) on the extraction efficiency $\left(E=\left(C_{t} V_{t}\right) /\left(C_{t} V_{t}+C_{b} V_{b}\right)\right)$ and purity $\left(A_{565} / A_{280}\right)$. Bars donate standard deviation (repeating three times). ChCl-U represents choline chloride-urea, D-ChCl-Gl represents choline chloride-D-glucose, $\mathrm{ChCl}-\mathrm{G}$ represents choline chloride-glycerol, $\mathrm{D}-\mathrm{ChCl}-\mathrm{F}$ represents choline chloride-D-fructose, D-ChCl-S represents choline chloride-D-sorbitol, $\mathrm{ChCl}$-EG represents choline chloride-ethylene glycol.

\subsection{Single-Factor Experiments}

To ascertain the impact of the amount of DES on the extraction efficiency and purity of R-PE, different amounts of ChCl-U $(0.25-0.55 \mathrm{~g})$ were mixed into six copies of the $\mathrm{K}_{2} \mathrm{HPO}_{4}$ solution $(0.8 \mathrm{~g} / \mathrm{mL}$, $0.5 \mathrm{~mL}$ ) to compose ATPS. The same volume of dialyzed R-PE was added to the ATPSs and mixed the systems again. After phase separation, the extraction efficiency and purity could be obtained by measuring the absorbance at the corresponding wavelengths and calculating by the relevant equations. It was discovered that $0.35 \mathrm{~g}$ was the most suitable amount of DES for the optimal extraction conditions (Figure 3a). This trend was because an increased amount of DES resulted in high viscosity of the top 
phase, preventing R-PE from transferring into the top phase [35]. This result was similar to that for $\mathrm{ChCl}-\mathrm{U} / \mathrm{K}_{2} \mathrm{HPO}_{4}(0.7 \mathrm{~g} / \mathrm{mL}, 2.0 \mathrm{~mL}, 1.4 \mathrm{~g})$ [37] and betaine-urea (Be-U) $/ \mathrm{K}_{2} \mathrm{HPO}_{4}(0.75 \mathrm{~g} / \mathrm{mL}, 2.0 \mathrm{~mL}$, $1.4 \mathrm{~g})$ [38] and higher than that of choline chloride-glycerol (ChCl-G) $/ \mathrm{K}_{2} \mathrm{HPO}_{4}(0.9 \mathrm{~g} / \mathrm{mL}, 2.0 \mathrm{~mL}$, $1.3 \mathrm{~g})$ [35], found in previous studies.

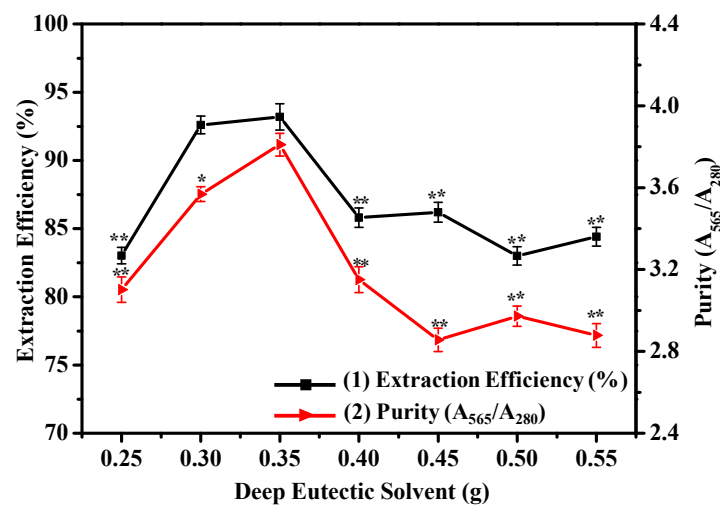

(a)

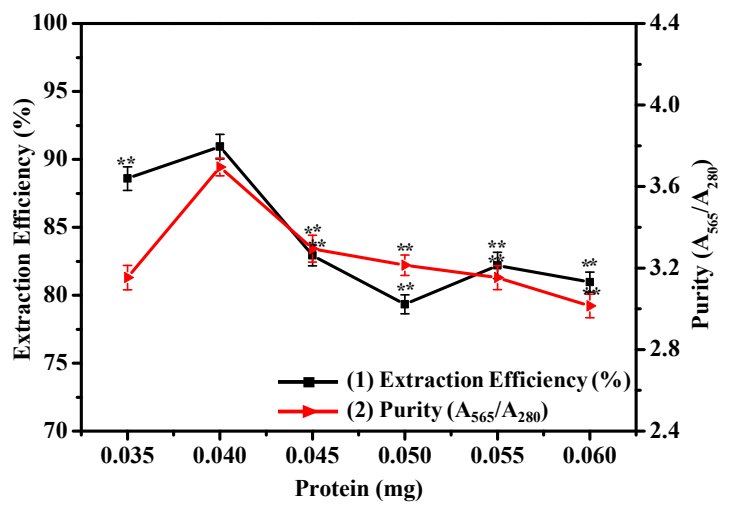

(b)

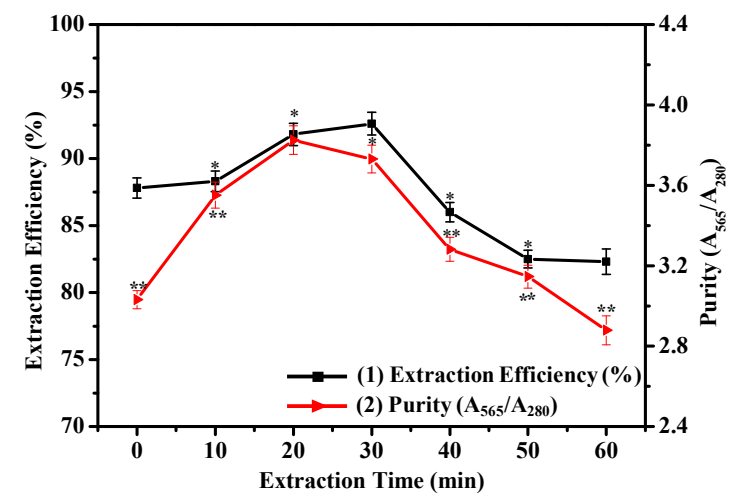

(c)

Figure 3. Effect of (a) amount of deep eutectic solvent (DES), (b) amount of R-PE, and (c) extraction time on the extraction efficiency $\left(E=\left(C_{t} V_{t}\right) /\left(C_{t} V_{t}+C_{b} V_{b}\right)\right)$ and purity $\left(A_{565} / A_{280}\right)$ in the DES/K ${ }_{2} H_{P O}$ ATPS. Bars donate standard deviation (repeating three times). Asterisks represent statistical significance $\left.{ }^{*} p \leq 0.05 ;{ }^{* *} p \leq 0.01 ; \mathrm{ns}, p>0.05\right)$.

It was clear that the extraction efficiency and purity increased with the increasing amount of R-PE lower than $0.040 \mathrm{mg}$ and decreased when the amount of R-PE was higher than $0.040 \mathrm{mg}$ (Figure 3b). Therefore, the optimum amount of R-PE was $0.040 \mathrm{mg}$. The possible reason for this phenomenon was that an increase in the amount of R-PE led to high extraction efficiency and purity, and with a further increase in the amount of R-PE, the extraction system approached saturation, leading to extraction efficiency and purity reduction [38].

As shown in Figure 3c, the maximal extraction efficiency and purity were acquired when the extraction times were 30 and $20 \mathrm{~min}$, respectively. Considering extraction efficiency, purity, and energy saving, the optimal extraction time was $20 \mathrm{~min}$. With the increase in time, the R-PE in the top phase escaped from the package of the DES to the bottom phase, leading to a decline of the extraction efficiency and purity [35]. Under optimal conditions, the extraction efficiency of R-PE could reach $92.60 \%$, and the purity of R-PE reached 3.825 (the ratio of $\mathrm{A}_{565} / \mathrm{A}_{280}$ ), up to drug-grade (3.0).

With the aim of validating feasibility of the method, precision, repeatability, and stability experiments were conducted (Table S1). The relative standard deviations (RSDs) of three experiments 
were $0.92,0.85$, and $0.73 \%(n=5)(<10 \%)$, respectively, which indicated that the method had acceptable feasibility.

\subsection{Electrophoresis Assay of Purified R-PE}

The SDS-PAGE result of the fractions collected during the purification steps is shown in Figure 4. It revealed that impurities were almost completely removed after purification in the ATPS, proving the effectiveness of this purification method. It can also be seen from the SDS-PAGE, as shown by zinc acetate staining, that the purified R-PE contained three fluorescent bands (Figure $4 \mathrm{a}$, lane 7 and 8), representing the formation of fluorescent chelates between the phycobilirubin of R-PE and zinc ions. Moreover, it was found that three subunits of R-PE ( $\alpha, \beta$ and $\gamma$ subunits) appeared in the same position in the SDS-PAGE, as shown by Coomassie blue R-250 staining (Figure 4b, lane 7 and 8), whose molecular masses were about 18.0,21.0, and $30.0 \mathrm{kDa}$. The previous report confirmed the presence of three similar characteristic subunits of about 17, 19, and $33 \mathrm{kDa}$ in R-PE from P. yezoensis [39].

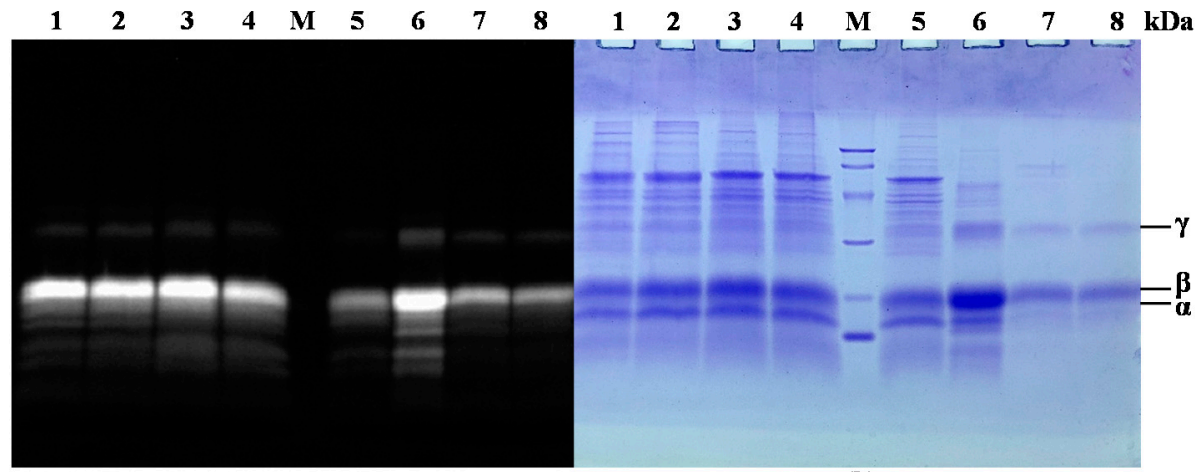

(a)

(b)

Figure 4. SDS-PAGE stained with zinc acetate (a) and Coomassie blue R-250 (b) of the fractions collected during the extraction and purification steps. Lanes 1-4, first to fourth frozen and thawing extract (crude extract); lane M, molecular mass markers (from top to bottom: 97.2, 66.4, 44.2, 29.0, 20.1, and 14.3 kDa); lane 5, first ammonium sulphate precipitation supernatant; lane 6, dialyzed R-PE; lane 7, purified R-PE by DES-ATPS (about $0.035 \mathrm{mg}$ ); lane 8, purified R-PE by DES-ATPS (about $0.030 \mathrm{mg}$ ).

The results of native-PAGE, as shown by the zinc acetate staining (Figure 5a) and Coomassie blue R-250 staining (Figure 5b), showed that the components of fluorescent protein gradually presented one band during the whole purification process. As shown in Figure 5b, only one band was presented as well (lane 7 and 8), indicating that the purified R-PE was homogenous.

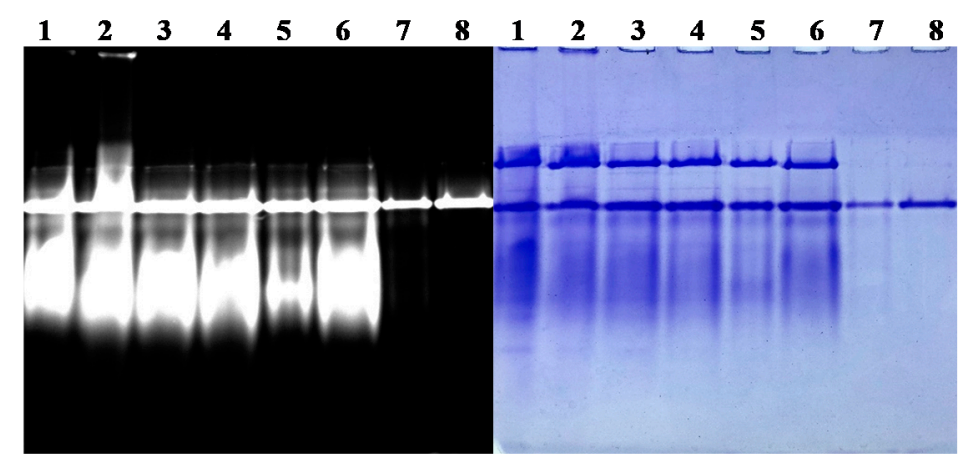

(a)

(b)

Figure 5. Native-PAGE stained with zinc acetate (a) and Coomassie blue R-250 (b) of the fractions during the extraction and purification steps. Lanes 1-4, first to fourth frozen and thawing extract (crude extract); lane 5, first ammonium sulphate precipitation supernatant; lane 6, dialyzed R-PE; lane 7, purified R-PE by DES-ATPS (about $0.030 \mathrm{mg}$ ); lane 8, purified R-PE by DES-ATPS (about $0.035 \mathrm{mg}$ ). 


\subsection{R-PE Purity and Yield Analysis}

The total protein content, R-PE content, yield, and purity after each purification step were calculated and are shown in Table 1, in order to study the change in R-PE during the whole purification process. It can be seen that the purity increased and R-PE content, protein content, and yield decreased due to loss in the purification process. The purity of R-PE could be improved from 0.713 to 3.825 , and the extraction yield for the DES phase in relation to the first frozen-thawing extract was $69.99 \%$.

Table 1. Purity and other index of R-PE from P. yezoensis after each stage of purification.

\begin{tabular}{ccccc}
\hline Purification Step & $\begin{array}{c}\text { Total Protein } \\
\text { Content }(\mathbf{m g})\end{array}$ & R-PE Content (mg) & Yield (\%) & Purity ( $\left.\mathbf{A}_{\mathbf{5 6 5}} / \mathbf{A}_{\mathbf{2 8 0}}\right)$ \\
\hline $\begin{array}{c}\text { First to fourth frozen-thawing } \\
\text { extract (crude extract) } \\
\begin{array}{c}\text { Two-step salting-out } \\
\text { extraction (dialyzed R-PE) }\end{array}\end{array}$ & 174.62 & 88.29 & 94.43 & 0.713 \\
$\begin{array}{c}\text { R-PE after aqueous two-phase } \\
\text { system (ATPS) }\end{array}$ & 96.94 & 70.68 & 75.59 & 2.293 \\
\hline
\end{tabular}

Total protein content was determined by the Bradford method; R-PE yield = (R-PE content after purification)/(R-PE content in first frozen-thawing extract).

\subsection{Characterization of R-PE Properties and Mechanism of Purification Method Based on DES-ATPS}

\subsubsection{Characterization of R-PE Optical Properties before and after Purification}

UV-vis spectra and fluorescence spectra were measured to characterize the spectral properties of R-PE. As shown in Figure 6a, R-PE had two absorbance peaks at 495 and $565 \mathrm{~nm}$, and a shoulder at $540 \mathrm{~nm}$. R-PE exhibited an excitation wavelength at $495 \mathrm{~nm}$ and emission wavelength at $570 \mathrm{~nm}$ (Figure 6b). These optical properties of R-PE were in accordance with those of R-PE purified by conventional purification methods such as hydroxyapatite chromatography [20] and DEAE-Sepharose Fast Flow chromatography [1], which could prove the effectiveness of DES-ATPS. Further, the spectra followed a similar trend before and after purification. These results suggested that there were neither interaction effects nor chemical bonds formed between the R-PE and DESs, which further demonstrated that the spatial structure of R-PE was not destroyed [40].

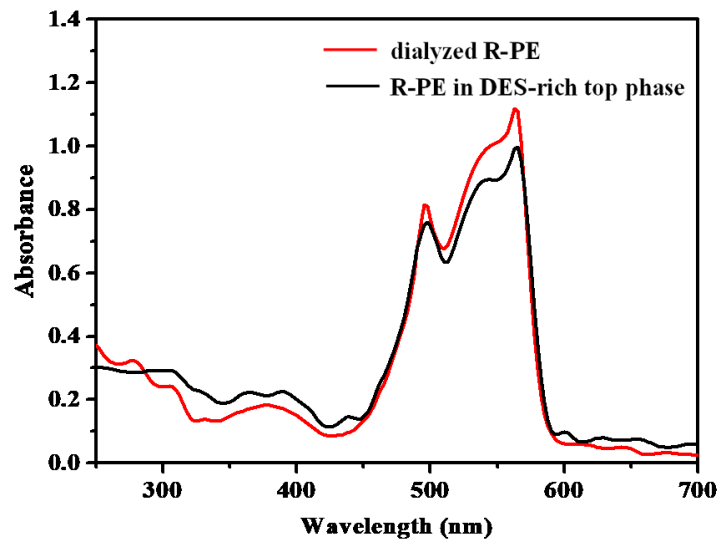

(a)

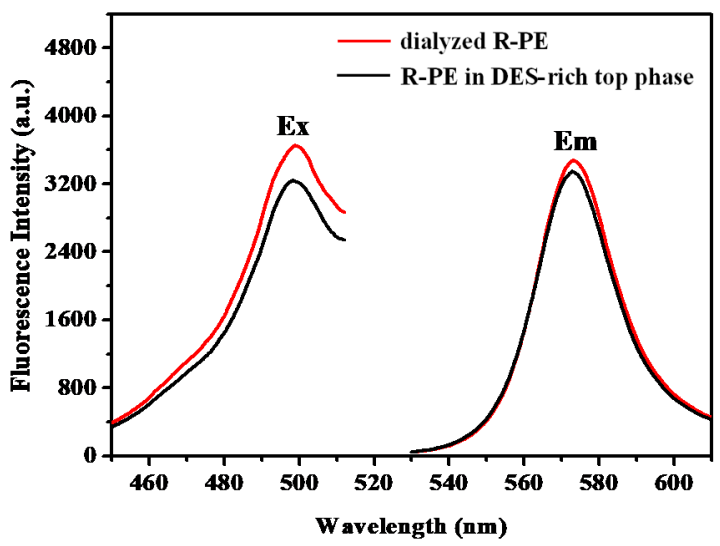

(b)

Figure 6. (a) UV-vis spectra of dialyzed R-PE and R-PE in deep eutectic solvent (DES)-rich top phase after extraction; $(\mathbf{b})$ excitation wavelength $\left(E_{\mathrm{x}}\right)$ and emission wavelength $\left(E_{\mathrm{m}}\right)$ of dialyzed R-PE and R-PE in DES-rich top phase after extraction.

The use of FT-IR spectra is to investigate functional groups or chemical bonds in a molecule of an interaction system. Figure 7 (black and blue lines) indicates that the absorption bands of DES $\left(1472 \mathrm{~cm}^{-1}\right)$ 
and dialyzed R-PE $\left(1074 \mathrm{~cm}^{-1}\right)$ were recognizable in the spectra before extraction. After extraction, these two bands were still identifiable in the spectra of R-PE-DES complexity (red line). This suggested that the functional groups of R-PE were maintained well, indicating that the structure of the R-PE was not changed. In the previous studies, DES-based ATPS, such as ChCl-glycerol/ $\mathrm{K}_{2} \mathrm{HPO}_{4}$ [35] and betaine-urea/ $\mathrm{K}_{2} \mathrm{HPO}_{4}$ [41], also maintained the structure and activity of the protein during the extraction process, which made such systems competitive candidates in the field of extracting proteins.

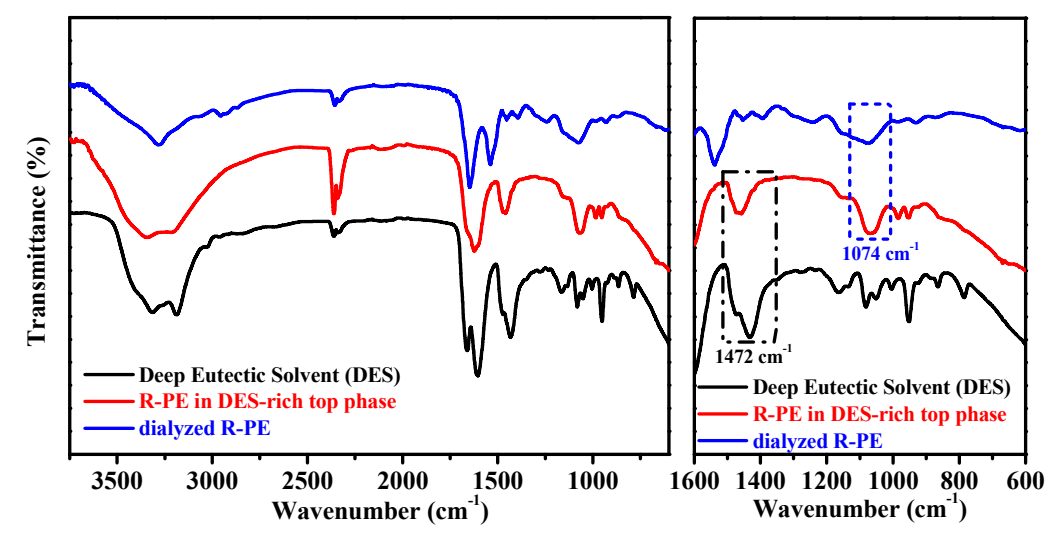

Figure 7. FT-IR spectra analysis of deep eutectic solvent (DES) (black line), R-PE in DES-rich top phase (red line), and dialyzed R-PE (blue line).

\subsubsection{Characterization of R-PE by Circular Dichroism Spectra before and after Purification}

Circular dichroism (CD) spectra were measured to characterize the secondary structure of dialyzed R-PE and R-PE in the DES-rich top phase. As shown in Figure 8, the CD spectra of dialyzed R-PE showed negative ellipticity between 202 and $240 \mathrm{~nm}$ (minima 208 and $222 \mathrm{~nm}$ ) and positive ellipticity at $192 \mathrm{~nm}$, corresponding to the CD spectral characteristics of $\alpha$-helical proteins [42]. It was deduced that R-PE mainly contains $\alpha$-helix, and the results were in accordance with previous reports [43]. The CD spectra curve of dialyzed R-PE was similar to that of R-PE in the DES-rich top phase, which indicated that the secondary structure of R-PE was maintained well during the purification process.

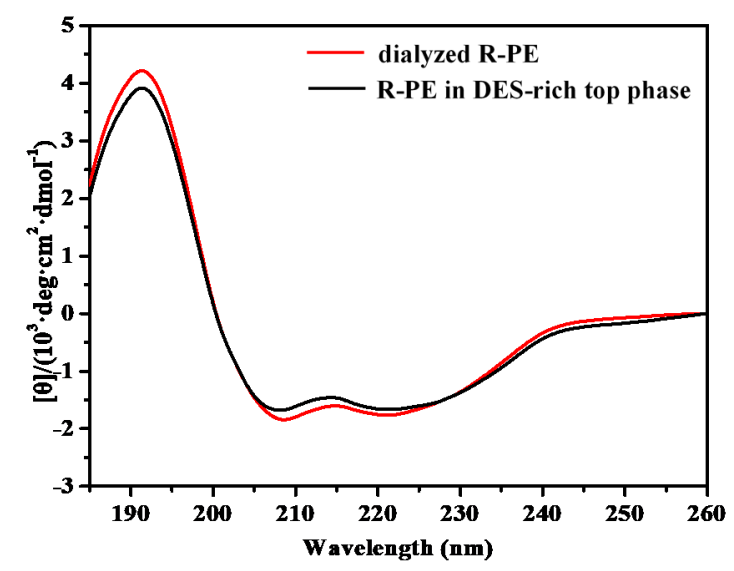

Figure 8. CD spectra of dialyzed R-PE and R-PE in deep eutectic solvent (DES)-rich top phase after extraction.

\subsubsection{Mechanism of the Purification Method Based on DES-ATPS}

In order to further study the driving forces of the extraction process, TEM was carried out to examine the morphology of the DES and dialyzed R-PE (before extraction and in the DES-rich top phase after extraction). The size of the dialyzed R-PE was about $800 \mathrm{~nm}$. The conformation of the 
DES-rich top phase without R-PE was in a state of less aggregation (Figure 9b). After adding the dialyzed R-PE extract, the DES encircled the R-PE particles and the complex took shape (Figure 9c). DES could form DES micelles to aggregate R-PE to the DES-rich top phase [38]. Therefore, it was deduced that the "aggregation and surrounding phenomenon" [33] were the main driving force in the extraction process by the DES-based ATPS. The results were similar to those reported in previous literature [38].

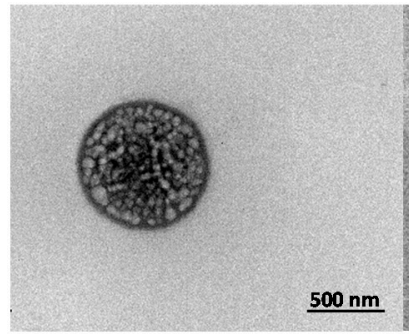

(a)

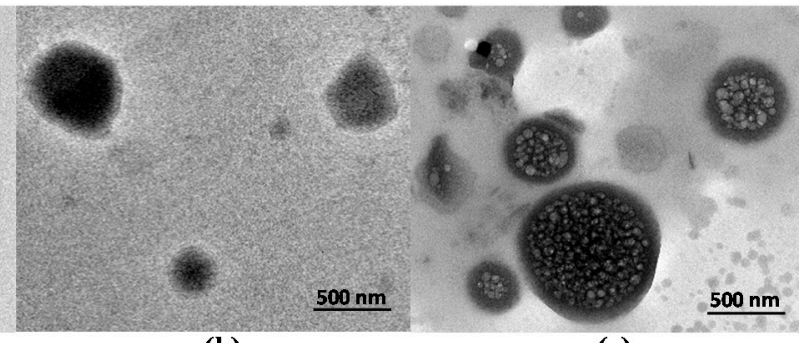

(b) (c)

Figure 9. TEM images in the extraction process. (a) Dialyzed R-PE before extraction, (b) deep eutectic solvent (DES) before extraction, and (c) DES-rich top phase after extraction.

\subsection{Comparison with Other Purification Methods}

For comparative purpose, Table 2 summarizes several reported methods for R-PE extraction. In this study, the purity of R-PE was higher than that achieved by DEAE-Sepharose Fast Flow chromatography [1] and ATPS (PEG 1450/ $\left.\mathrm{K}_{3} \mathrm{PO}_{4}\right)$ [44], lower than that of chromatography combined with other pretreatment methods [2,21,45], and close to that of hydroxyapatite column chromatography [14]. The extraction yield of the present study was lower than for ATPS (PEG 1450/ $\mathrm{K}_{3} \mathrm{PO}_{4}$ ) [44] and higher than for other methods mentioned in Table 2. In this research, the developed DES-ATPS had the advantages of being green and simple, which makes it a promising alternative for extracting water-soluble components including value-added R-PE.

Table 2. Comparison of this work with various reported methods for R-PE extraction.

\begin{tabular}{|c|c|c|c|c|}
\hline Method & Source & Yield (\%) & Purity $\left(A_{565} / A_{280}\right)$ & References \\
\hline $\begin{array}{c}\text { DEAE-Sepharose Fast Flow } \\
\text { chromatography } \\
\text { Gel filtration }+\end{array}$ & Grateloupia turuturu & 27.00 & 2.890 & [1] \\
\hline $\begin{array}{c}\text { DEAE-Sepharose Fast Flow } \\
\text { chromatography }\end{array}$ & Heterosiphonia japonica & none & 4.890 & [2] \\
\hline $\begin{array}{l}\text { Ammonium sulfate } \\
\text { precipitation +DEAE-Sepharose } \\
\text { Fast Flow chromatography }\end{array}$ & Polysiphonia urceolata & 67.33 & 5.600 & {$[45]$} \\
\hline $\begin{array}{l}\text { Ammonium sulfate } \\
\text { precipitation }+ \text { Q-Sepharose } \\
\text { column chromatography }\end{array}$ & Portieria hornemannii & 64.80 & 5.210 & {$[21]$} \\
\hline $\begin{array}{l}\text { Hydroxyapatite } \\
\text { chromatography }\end{array}$ & Polysiphonia urceolata & 22.00 & 3.900 & {$[14]$} \\
\hline $\begin{array}{l}\text { Aqueous two-phase system } \\
\left.\text { (ATPS) (PEG 1450/K } \mathrm{KOO}_{4}\right)\end{array}$ & Gelidium pusillum & 72.00 & 1.100 & {$[44]$} \\
\hline $\begin{array}{l}\text { Deep eutectic solvent aqueous } \\
\text { two-phase system (DES-ATPS) } \\
\text { (choline chloride-urea/ } \mathrm{K}_{2} \mathrm{HPO}_{4} \text { ) }\end{array}$ & P. yezoensis & 69.99 & 3.825 & This work \\
\hline
\end{tabular}

R-PE yield = (R-PE content after purification)/(R-PE content in first frozen-thawing extract). 


\section{Materials and Methods}

\subsection{Materials}

Choline chloride $\left(\mathrm{C}_{5} \mathrm{H}_{14} \mathrm{ClNO}\right)$ (dried in a DZF-6051 vacuum drying oven (Shanghai, China) for about $2 \mathrm{~h}$ at $110{ }^{\circ} \mathrm{C}$ before use), urea $\left(\mathrm{CO}\left(\mathrm{NH}_{2}\right)_{2}\right)$, D-sorbitol $\left(\mathrm{C}_{6} \mathrm{H}_{14} \mathrm{O}_{6}\right)$, D-(+)-glucose $\left(\mathrm{C}_{6} \mathrm{H}_{12} \mathrm{O}_{6}\right)$, ethylene glycol $\left(\left(\mathrm{CH}_{2} \mathrm{OH}\right)_{2}\right)$, D-(-)-fructose $\left(\mathrm{C}_{6} \mathrm{H}_{12} \mathrm{O}_{6}\right)$, glycerol $\left(\mathrm{C}_{3} \mathrm{H}_{8} \mathrm{O}_{3}\right)$, and $\mathrm{K}_{2} \mathrm{HPO}_{4}$ were purchased from Sinopharm Chemical Reagent Co., Ltd. All of these reagents were of analytical grade. Dried seaweed (P. yezoensis) was purchased from Yantai, Shandong Province, China. Ultrafiltration centrifuge tube (MWCO $10 \mathrm{kDa}$ ) was purchased from Merck KGaA (Darmstadt, Germany). Protein Molecular Weight Marker 3450Q (Takara Biomedical Technology (Beijing) Co., Ltd., Beijing, China) was used as the molecular weight marker.

\subsection{R-PE Pre-Treatment from P. yezoensis}

A total of $5.0 \mathrm{~g}$ of $P$. yezoensis was weighed and washed with phosphate buffer $(\mathrm{PB}, 10 \mathrm{mM}, \mathrm{pH}$ 6.8) and repeatedly frozen and thawed four times $\left(-25^{\circ} \mathrm{C}\right.$ and $\left.4{ }^{\circ} \mathrm{C}\right)$ [39]. The obtained slurry was filtrated by gauze, then centrifuged $\left(7500 \times \mathrm{g}, 20 \mathrm{~min}, 4^{\circ} \mathrm{C}\right)$; this was the crude extract. The crude extract was precipitated with $\left(\mathrm{NH}_{4}\right)_{2} \mathrm{SO}_{4}$ at saturation of $10 \%\left(5.5 \mathrm{~g}\left(\mathrm{NH}_{4}\right)_{2} \mathrm{SO}_{4}\right.$ added per $100 \mathrm{~mL}$ of the crude extract). After it was placed in static conditions for $8 \mathrm{~h}$ at $4{ }^{\circ} \mathrm{C}$, it was centrifuged $(7500 \times g$, $\left.20 \mathrm{~min}, 4^{\circ} \mathrm{C}\right)$ to obtain the supernatant. Then, the supernatant was precipitated with $\left(\mathrm{NH}_{4}\right)_{2} \mathrm{SO}_{4}$ at a saturation of $50 \%\left(25.1 \mathrm{~g}\left(\mathrm{NH}_{4}\right)_{2} \mathrm{SO}_{4}\right.$ added per $100 \mathrm{~mL}$ of the supernatant) and left for $8 \mathrm{~h}$ at $4{ }^{\circ} \mathrm{C}$. With the same centrifuge process mentioned above, the precipitate was obtained. The final precipitate was dissolved and dialyzed with an MWCO 8000 Da dialysis cassette against $500 \mathrm{~mL}$ of PB solution (10 mM, pH 6.8), and the fresh buffer was changed every half hour. After about six hours, $0.5 \mathrm{~mL}$ dialysate was taken into a $1.5 \mathrm{~mL}$ centrifuge tube, and $0.5 \mathrm{~mL} 0.1 \mathrm{M} \mathrm{BaCl}_{2}$ was added. No white precipitation production indicated that there was no $\left(\mathrm{NH}_{4}\right)_{2} \mathrm{SO}_{4}$ in the dialysate, implying the end of the dialysis process. The obtained solution was called dialyzed R-PE.

\subsection{Deep Eutectic Solvents Preparation}

Six kinds of deep eutectic solvents (DES) were synthesized by stirring the eutectic mixtures at $80^{\circ} \mathrm{C}$ for about $2 \mathrm{~h}$, until a homogenous liquid was formed. The ratios of quaternary ammonium salts (choline chloride) to hydrogen bond donors (Ethylene glycol, D-sorbitol, glycerol, D-(+)-glucose, D-fructose, and urea) were 1:2, 1:1,1:2, 2:1, 1.9:1, and 1:2, respectively [35,46]. The structures of the obtained DESs were confirmed by an FT-IR spectrometer (TENSOR, Bruker Optics, Karlsruhe, Germany).

\subsection{Establishment and Phase Behavior Study of the DES-Based ATPS}

For the phase diagrams determination, the cloud point titration method was used, based on atmospheric pressure and room temperature [47]. A total of $2.0 \mathrm{~g}$ of the DES was weighed into a $10 \mathrm{~mL}$ centrifuge tube, then $1.0 \mathrm{~g} / \mathrm{mL}$ of $\mathrm{K}_{2} \mathrm{HPO}_{4}$ solution was added drop by drop to the centrifuge tube and shaken until the mixture became cloudy, indicating DES/K${ }_{2} \mathrm{HPO}_{4}$ ATPS formation. The mass of $\mathrm{K}_{2} \mathrm{HPO}_{4}$ solution added was recorded. Then, a certain volume of ultrapure water was added to the system dropwise until phase one occurred. The mass of water was also recorded after its addition (the mass difference of the system before and after adding the water). Finally, the process above was repeated to construct the phase diagrams of liquid-liquid equilibrium. The $\mathrm{X}$ axis and $\mathrm{Y}$ axis represented the mass fraction of the $\mathrm{K}_{2} \mathrm{HPO}_{4}$ solution and DES, respectively.

\subsection{Selection of DES-ATPS for the R-PE Extraction}

In order to select the suitable DES-ATPS for R-PE extraction, $0.35 \mathrm{~g}$ of six kinds of DESs were weighed into six $1.5 \mathrm{~mL}$ centrifuge tubes and of $\mathrm{K}_{2} \mathrm{HPO}_{4}$ solution $(0.8 \mathrm{~g} / \mathrm{mL}, 0.5 \mathrm{~mL})$ were added into the centrifuge tubes to compose ATPS. Then, six copies of the same mass of dialyzed R-PE $(0.040 \mathrm{mg})$ 
were added into ATPSs. The extraction efficiency and purity were calculated using the following equations from the absorbance measured at the corresponding wavelengths.

The efficiency of R-PE in the two-phase system was calculated by the following equations:

$$
\mathrm{E}=\left(\mathrm{C}_{\mathrm{t}} \mathrm{V}_{\mathrm{t}}\right) /\left(\mathrm{C}_{\mathrm{t}} \mathrm{V}_{\mathrm{t}}+\mathrm{C}_{\mathrm{b}} \mathrm{V}_{\mathrm{b}}\right)
$$

where $C_{t}$ and $C_{b}$ are the concentrations of the R-PE in the DES-rich top phase and salt-rich bottom phase, respectively. $V_{t}$ and $V_{b}$ represent the volume of the top phase and the bottom phase, respectively.

Purity was calculated by the following formula [45]:

$$
\text { Purity }=\mathrm{A}_{565} / \mathrm{A}_{280}
$$

where $A_{565}$ and $A_{280}$ are the absorbance of R-PE at 280 and $565 \mathrm{~nm}$, respectively.

\subsection{Single-Factor Experiments}

Based on the selected ATPS above, single-factor experiments were performed by varying one factor varied at different levels, while the other factors were fixed, in order to explore the optimum conditions for the extraction efficiency (E) and purity of R-PE. First of all, different amount of DES $(0.25,0.30,0.35,0.40,0.45,0.50$, and $0.55 \mathrm{~g})$ were added into six copies of the $\mathrm{K}_{2} \mathrm{HPO}_{4}$ solution $(0.8 \mathrm{~g} / \mathrm{mL}$, $0.5 \mathrm{~mL}$ ) to compose ATPS. A certain mass of dialyzed R-PE was added to the system. After phase separation, the top phase was filtered through ultrafiltration centrifuge tube (MWCO $10 \mathrm{kDa})(4500 \times \mathrm{g}$, $10 \mathrm{~min}, 4^{\circ} \mathrm{C}$ ) to obtain purified R-PE, which was needed in the following analysis. The extraction efficiency and purity were calculated using the relevant equations. Then, the influence of different amounts of dialyzed R-PE $(0.035,0.040,0.045,0.050,0.055$, and $0.060 \mathrm{mg})$ and extraction times $(0,10,20$, $30,40,50$, and $60 \mathrm{~min}$ ) on extraction efficiency and purity were studied in the same way, respectively.

Under the selected optimal conditions above, precision, repeatability, and stability experiments were accomplished to validate the feasibility of the method. Apparatus precision was determined through five parallel measurements of the top phase under the same conditions. The repeatability was validated by taking five copies of one sample under the same conditions. The stability was determined over five consecutive days under the same conditions.

\subsection{Electrophoresis Assay of Purified R-PE}

SDS-PAGE was carried out using 15\% separating and 5\% stacking gel based on a previous study with some modification (70 V voltage for the initial $20 \mathrm{~min}$ and then $85 \mathrm{~V}$ until the end) [48]. Native-PAGE was performed with $10 \%$ separating and $5 \%$ stacking gel according to the previous literature with some modification ( $70 \mathrm{~V}$ for the initial $20 \mathrm{~min}$ and then $85 \mathrm{~V}$ until the end) [49]. After gel electrophoresis, the gel was soaked in $20 \mathrm{mM}$ zinc acetate solution for $5 \mathrm{~min}$ at room temperature. After rinsing with double-distilled water four times (1-2 min each time), the gel was stained by Coomassie blue R-250 $(0.1 \%, w / v)$. The gel electrophoresis results were analyzed by the ChemiDoc XRS+ system (Bio-Rad, Berkeley, CA, USA).

\subsection{R-PE Purity and Yield Analysis}

In order to study the purity and yield change in R-PE throughout the whole purification process, the total protein content, R-PE content, yield, and purity after each purification step were measured and calculated. The total protein content was determined by the Bradford method. The purity, R-PE concentration, and yield were calculated by Equations (2)-(4).

The concentration of R-PE was measured using the method from a previous report [50] with some modifications:

$$
\mathrm{R} \text { - phycoerythrin }(\mathrm{mg} / \mathrm{mL})=\left(0.123 \mathrm{~A}_{565}-0.068 \mathrm{~A}_{618}+0.015 \mathrm{~A}_{650}\right) \times n
$$


where $A_{565}, A_{618}$, and $A_{650}$ are the absorbance of R-PE at 565,618 , and $650 \mathrm{~nm}$, respectively. $n$ represents the dilution fold.

The R-PE yield from total protein was calculated by the following equation:

$$
\mathrm{R}-\mathrm{PE} \text { yield }=\frac{\mathrm{R}-\mathrm{PE} \text { content after purification }}{\mathrm{R}-\mathrm{PE} \text { content in first frozen }- \text { thawing extract }}
$$

\subsection{R-PE Properties Characterization and Measurement of the Extraction Mechanism}

The UV spectra of the purified samples were obtained using a UV-vis spectrophotometer (UV2450, Shimadzu, Kyoto, Japan). Fluorescence spectra of the samples were measured using a fluorescence spectrometer (F-2700, Hitachi, Tokyo, Japan). FTIR spectra were recorded at room temperature on an FTIR spectrometer (TENSOR, Bruker Optics, Karlsruhe, Germany). The secondary structure was measured using a Circular Dichroism (CD) Spectrometer (MOS-500, Bio-Logic, Paris, France). The microstructure of the samples was examined with a transmission electron microscope (JEOL-2100, JEOL, Tokyo, Japan). The experimental data analysis was performed by Origin 8.5.

\subsection{Statistical Analysis}

Statistical significance of the results was analyzed by Statistical Product and Service Solutions (SPSS) 19.0 software. Asterisks represented statistical significance $\left({ }^{*} p \leq 0.05 ;{ }^{* *} p \leq 0.01 ; \mathrm{ns}, p>0.05\right)$.

\section{Conclusions}

In view of the wide application of R-PE in the drug and food fields, in this work, the marine bioactive protein R-PE was purified from P. yezoensis using green DES combined with ATPS. Under the optimal conditions, a final yield of $69.99 \%$ and purity of 3.825 were achieved with this system. UV-vis, fluorescence, FT-IR spectra, and circular dichroism spectra illustrated that the spatial structure and secondary structure of R-PE were maintained throughout the whole process. The aggregation and embrace phenomena drove the extraction of R-PE in the separation process by TEM. This green and simple purification method based on DES-ATPS may offer new possibilities for obtaining more active drug molecules from marine algae.

Supplementary Materials: The following are available online at http://www.mdpi.com/1660-3397/18/12/618/s1, Figure S1: Infrared spectroscopy of six deep eutectic solvents: (a) choline chloride-ethylene glycol (ChCl-EG), (b) choline chloride-D-sorbitol (D-ChCl-S), (c) choline chloride-glycerol (ChCl-G), (d) choline chloride-D-glucose (D-ChCl-Gl), (e) choline chloride-D-fructose (D-ChCl-F), (f) choline chloride-urea (ChCl-U); Table S1: The results of the precision, repeatability, and stability experiments.

Author Contributions: All authors made equal contributions to preparing this manuscript. Conceptualization, Y.X. and Q.W.; validation, Y.X.; investigation, Y.X.; formal analysis, Y.X.; writing-original draft, Y.X. and Q.W.; supervision, Q.W.; project administration, Q.W. and Y.H.; funding acquisition, Q.W. and Y.H. All authors have read and agreed to the published version of the manuscript.

Funding: This study was funded by the National Natural Science Foundation of China (41876149), the Key Research and Development Plan of Shandong Province (2018GHY115021, 2019GHY112031) and the Natural Science Foundation of Shandong Province (ZR2019MD018).

Conflicts of Interest: The authors declare no conflict of interest.

\section{References}

1. Munier, M.; Morancais, M.; Dumay, J.; Jaouen, P.; Fleurence, J. One-step purification of R-phycoerythrin from the red edible seaweed Grateloupia Turuturu. J. Chromatogr. B-Anal. Technol. Biomed. Life Sci. 2015, 992, $23-29$. [CrossRef] [PubMed]

2. Sun, L.; Wang, S.; Gong, X.; Zhao, M.; Fu, X.; Wang, L. Isolation, purification and characteristics of R-phycoerythrin from a marine macroalga Heterosiphonia Japonica. Protein Expr. Purif. 2009, 64, 146-154. [CrossRef] [PubMed] 
3. Isaka, S.; Cho, K.; Nakazono, S.; Abu, R.; Ueno, M.; Kim, D.; Oda, T. Antioxidant and anti-inflammatory activities of porphyran isolated from discolored nori (Porphyra yezoensis). Int. J. Biol. Macromol. 2015, 74, 68-75. [CrossRef]

4. Fleurence, J.; Morancais, M.; Dumay, J.; Decottignies, P.; Turpin, V.; Munier, M.; Garcia-Bueno, N.; Jaouen, P. What are the prospects for using seaweed in human nutrition and for marine animals raised through aquaculture? Trends Food Sci. Technol. 2012, 27, 57-61. [CrossRef]

5. Dumay, J.; Clement, N.; Morancais, M.; Fleurence, J. Optimization of hydrolysis conditions of Palmaria palmata to enhance R-phycoerythrin extraction. Bioresour. Technol. 2013, 131, 21-27. [CrossRef]

6. Jiang, Z.; Hama, Y.; Yamaguchi, K.; Oda, T. Inhibitory effect of sulphated polysaccharide porphyran on nitric oxide production in lipopolysaccharide-stimulated RAW264.7 macrophages. J. Biochem. 2012, 151, 65-74. [CrossRef]

7. Eduardo Sosa-Hernandez, J.; Isabel Rodas-Zuluaga, L.; Castillo-Zacarias, C.; Rostro-Alanis, M.; De la Cruz, R.; Carrillo-Nieves, D.; Salinas-Salazar, C.; Grunewald, C.F.; Llewellyn, C.A.; Olguin, E.J.; et al. Light intensity and nitrogen concentration impact on the biomass and phycoerythrin production by Porphyridium Purpureum. Mar. Drugs 2019, 17, 460. [CrossRef]

8. Kersen, P.; Paalme, T.; Pajusalu, L.; Martin, G. Biotechnological applications of the red alga Furcellaria lumbricalis and its cultivation potential in the Baltic Sea. Bot. Mar. 2017, 60, 207-218. [CrossRef]

9. Wu, Q.; Fu, X.-P.; Sun, L.-C.; Zhang, Q.; Liu, G.-M.; Cao, M.-J.; Cai, Q.-F. Effects of physicochemical factors and in vitro gastrointestinal digestion on antioxidant activity of R-phycoerythrin from red algae Bangia Fusco-Purpurea. Int. J. Food Sci. Technol. 2015, 50, 1445-1451. [CrossRef]

10. Lee, D.; Nishizawa, M.; Shimizu, Y.; Saeki, H. Anti-inflammatory effects of dulse (Palmaria palmata) resulting from the simultaneous water-extraction of phycobiliproteins and chlorophyll a. Food Res. Int. 2017, 100, 514-521. [CrossRef]

11. Tan, H.; Gao, S.; Zhuang, Y.; Dong, Y.; Guan, W.; Zhang, K.; Xu, J.; Cui, J. R-phycoerythrin induces SGC-7901 apoptosis by arresting cellcycle at $S$ phase. Mar. Drugs 2016, 14, 166. [CrossRef]

12. Cian, R.E.; Lopez-Posadas, R.; Drago, S.R.; Sanchez De Medina, F.; Martinez-Augustin, O. Immunomodulatory properties of the protein fraction from Phorphyra columbina. J. Agric. Food Chem. 2012, 60, 8146-8154. [CrossRef] [PubMed]

13. Qi, H.; Liu, Y.; Qi, X.; Liang, H.; Chen, H.; Jiang, P.; Wang, D. Dietary recombinant phycoerythrin modulates the gut microbiota of H22 tumor-bearing mice. Mar. Drugs 2019, 17, 665. [CrossRef] [PubMed]

14. Niu, J.-F.; Wang, G.-C.; Tseng, C.-K. Method for large-scale isolation and purification of R-phycoerythrin from red alga Polysiphonia Urceolata Grev. Protein Expr. Purif. 2006, 49, 23-31. [CrossRef] [PubMed]

15. Huang, B.; Wang, G.C.; Zeng, C.K.; Li, Z.G. The experimental research of R-phycoerythrin subunits on cancer treatment: A new photosensitizer in PDT. Cancer Biother. Radiopharm. 2002, 17, 35-42. [CrossRef]

16. Kronick, M.N. The use of phycobiliproteins as fluorescent labels in immunoassay. J. Immunol. Methods 1986, 92, 1-13. [CrossRef]

17. Oi, V.T.; Glazer, A.N.; Stryer, L. Fluorescent phycobiliprotein conjugates for analyses of cells and molecules. J. Cell Biol. 1982, 93, 981-986. [CrossRef]

18. Sekar, S.; Chandramohan, M. Phycobiliproteins as a commodity: Trends in applied research, patents and commercialization. J. Appl. Phycol. 2008, 20, 113-136. [CrossRef]

19. Manirafasha, E.; Ndikubwimana, T.; Zeng, X.; Lu, Y.; Jing, K. Phycobiliprotein: Potential microalgae derived pharmaceutical and biological reagent. Biochem. Eng. J. 2016, 109, 282-296. [CrossRef]

20. Wang, Q.; Xu, Y.; Hou, Y.; Wang, Y.; Yan, M.; Zhang, X.; Wang, H. Highly sensitive and selective fluorescence detection of $\mathrm{Hg}(\mathrm{II})$ ions based on R-phycoerythrin from Porphyra Yezoensis. RSC Adv. 2016, 6, 114685-114689. [CrossRef]

21. Senthilkumar, N.; Suresh, V.; Thangam, R.; Kurinjimalar, C.; Kavitha, G.; Murugan, P.; Kannan, S.; Rengasamy, R. Isolation and characterization of macromolecular protein R-Phycoerythrin from Portieria Hornemannii. Int. J. Biol. Macromol. 2013, 55, 150-160. [CrossRef] [PubMed]

22. Ruiz-Ruiz, F.; Benavides, J.; Rito-Palomares, M. Scaling-up of a B-phycoerythrin production and purification bioprocess involving aqueous two-phase systems: Practical experiences. Process Biochem. 2013, 48, 738-745. [CrossRef] 
23. Chang, Y.-K.; Show, P.-L.; Lan, J.C.-W.; Tsai, J.-C.; Huang, C.-R. Isolation of C-phycocyanin from Spirulina platensis microalga using ionic liquid based aqueous two-phase system. Bioresour. Technol. 2018, 270, 320-327. [CrossRef] [PubMed]

24. Gai, Q.; Qu, F.; Zhang, T.; Zhang, Y. Integration of carboxyl modified magnetic particles and aqueous two-phase extraction for selective separation of proteins. Talanta 2011, 85, 304-309. [CrossRef] [PubMed]

25. Pang, J.; Sha, X.; Chao, Y.; Chen, G.; Han, C.; Zhu, W.; Li, H.; Zhang, Q. Green aqueous biphasic systems containing deep eutectic solvents and sodium salts for the extraction of protein. RSC Adv. 2017, 7, 49361-49367. [CrossRef]

26. Abbott, A.P.; Boothby, D.; Capper, G.; Davies, D.L.; Rasheed, R.K. Deep eutectic solvents formed between choline chloride and carboxylic acids: Versatile alternatives to ionic liquids. J. Am. Chem. Soc. 2004, 126, 9142-9147. [CrossRef] [PubMed]

27. Zhang, H.; Wang, Y.; Xu, K.; Li, N.; Wen, Q.; Yang, Q.; Zhou, Y. Ternary and binary deep eutectic solvents as a novel extraction medium for protein partitioning. Anal. Methods 2016, 8, 8196-8207. [CrossRef]

28. Pandey, A.; Rai, R.; Pal, M.; Pandey, S. How polar are choline chloride-based deep eutectic solvents? Phys. Chem. Chem. Phys. 2014, 16, 1559-1568. [CrossRef]

29. Starykevich, M.; Salak, A.N.; Ivanou, D.K.; Lisenkov, A.D.; Zheludkevich, M.L.; Ferreira, M.G.S. Electrochemical deposition of zinc from deep eutectic solvent on barrier alumina layers. Electrochim. Acta 2015, 170, 284-291. [CrossRef]

30. Zhao, H.; Zhang, C.; Crittle, T.D. Choline-based deep eutectic solvents for enzymatic preparation of biodiesel from soybean oil. J. Mol. Catal. B-Enzym. 2013, 85, 243-247. [CrossRef]

31. Kaltsa, O.; Lakka, A.; Grigorakis, S.; Karageorgou, I.; Batra, G.; Bozinou, E.; Lalas, S.; Makris, D.P. A green extraction process for polyphenols from elderberry (Sambucus nigra) flowers using deep eutectic solvent and ultrasound-assisted pretreatment. Molecules 2020, 25, 921. [CrossRef] [PubMed]

32. Bajkacz, S.; Adamek, J.; Sobska, A. Application of deep eutectic solvents and ionic liquids in the extraction of catechins from tea. Molecules 2020, 25, 3216. [CrossRef] [PubMed]

33. Zeng, Q.; Wang, Y.; Huang, Y.; Ding, X.; Chen, J.; Xu, K. Deep eutectic solvents as novel extraction media for protein partitioning. Analyst 2014, 139, 2565-2573. [CrossRef] [PubMed]

34. Zeng, Q.; Wang, Y.; Li, N.; Huang, X.; Ding, X.; Lin, X.; Huang, S.; Liu, X. Extraction of proteins with ionic liquid aqueous two-phase system based on guanidine ionic liquid. Talanta 2013, 116, 409-416. [CrossRef] [PubMed]

35. Xu, K.; Wang, Y.; Huang, Y.; Li, N.; Wen, Q. A green deep eutectic solvent-based aqueous two-phase system for protein extracting. Anal. Chim. Acta 2015, 864, 9-20. [CrossRef] [PubMed]

36. Freire, M.G.; Pereira, J.F.B.; Francisco, M.; Rodriguez, H.; Rebelo, L.P.N.; Rogers, R.D.; Coutinho, J.A.P. Insight into the interactions that control the phase behaviour of new aqueous biphasic systems composed of polyethylene glycol polymers and ionic liquids. Chem. A Eur. J. 2012, 18, 1831-1839. [CrossRef] [PubMed]

37. Duan, L.; Dou, L.-L.; Guo, L.; Li, P.; Liu, E.H. Comprehensive evaluation of deep eutectic solvents in extraction of bioactive natural products. ACS Sustain. Chem. Eng. 2016, 4, 2405-2411. [CrossRef]

38. Li, N.; Wang, Y.; Xu, K.; Huang, Y.; Wen, Q.; Ding, X. Development of green betaine-based deep eutectic solvent aqueous two-phase system for the extraction of protein. Talanta 2016, 152, 23-32. [CrossRef]

39. Niu, J.-F.; Chen, Z.-F.; Wang, G.-C.; Zhou, B.-C. Purification of phycoerythrin from Porphyra yezoensis Ueda (Bangiales, Rhodophyta) using expanded bed absorption. J. Appl. Phycol. 2010, 22, 25-31. [CrossRef]

40. Chen, J.; Wang, Y.; Zeng, Q.; Ding, X.; Huang, Y. Partition of proteins with extraction in aqueous two-phase system by hydroxyl ammonium-based ionic liquid. Anal. Methods 2014, 6, 4067-4076. [CrossRef]

41. Souza, R.L.; Lima, R.A.; Coutinho, J.A.P.; Soares, C.M.F.; Lima, A.S. Novel aqueous two-phase systems based on tetrahydrofuran and potassium phosphate buffer for purification of lipase. Process Biochem. 2015, 50, 1459-1467. [CrossRef]

42. Shang, L.; Wang, Y.; Jiang, J.; Dong, S. pH-dependent protein conformational changes in albumin: Gold nanoparticle bioconjugates: A spectroscopic study. Langmuir 2007, 23, 2714-2721. [CrossRef] [PubMed]

43. Bekasova, O.D.; Shubin, V.V.; Safenkova, I.V.; Kovalyov, L.I.; Kurganov, B.I. Structural changes in R-phycoerythrin upon CdS quantum dot synthesis in tunnel cavities of protein molecules. Int. J. Biol. Macromol. 2013, 62, 623-628. [CrossRef] [PubMed]

44. Mittal, R.; Sharma, R.; Raghavarao, K.S.M.S. Aqueous two-phase extraction of R-Phycoerythrin from marine macro-algae, Gelidium pusillum. Bioresour. Technol. 2019, 280, 277-286. [CrossRef] 
45. Liu, L.N.; Chen, X.L.; Zhang, X.Y.; Zhang, Y.Z.; Zhou, B.C. One-step chromatography method for efficient separation and purification of R-phycoerythrin from Polysiphonia Urceolata. J. Biotechnol. 2005, 116, 91-100. [CrossRef]

46. Bai, C.; Wei, Q.; Ren, X. Selective extraction of collagen peptides with high purity from cod skins by deep eutectic solvents. ACS Sustain. Chem. Eng. 2017, 5, 7220-7227. [CrossRef]

47. Chakraborty, A.; Sen, K. Impact of $\mathrm{pH}$ and temperature on phase diagrams of different aqueous biphasic systems. J. Chromatogr. A 2016, 1433, 41-55. [CrossRef]

48. Laemmli, U.K. Cleavage of structural proteins during the assembly of the head of bacteriophage T4. Nature 1970, 227, 680-685. [CrossRef]

49. Singh, N.K.; Parmar, A.; Madamwar, D. Optimization of medium components for increased production of C-phycocyanin from Phormidium ceylanicum and its purification by single step process. Bioresour. Technol. 2009, 100, 1663-1669. [CrossRef]

50. Gao, H.F. The variation in the contents of phycobiliproteins from Porphyra haitanensis collected in different growing stages. Oceanol. Limnol. Sin. 1993, 24, 645-648.

Publisher's Note: MDPI stays neutral with regard to jurisdictional claims in published maps and institutional affiliations.

(C) 2020 by the authors. Licensee MDPI, Basel, Switzerland. This article is an open access article distributed under the terms and conditions of the Creative Commons Attribution (CC BY) license (http://creativecommons.org/licenses/by/4.0/). 